\title{
Effects of the 2008 Global Economic Crisis on National Health Indicators: Results from the Korean National Health and Nutrition Examination Survey
}

\author{
Jung-Hyun Shin' ${ }^{1}$ Gyeongsil Lee', Jun-Suk Kim', Hyung-Seok Oh'1, Keun-Seung Lee', Yong Hur', Be-Long Cho ${ }^{1,2,3, *}$ \\ 'Department of Family Medicine, Seoul National University Hospital, Seoul, Korea \\ ${ }^{2}$ Advanced Institutes of Convergence Technology, Seoul National University, Suwon, Korea \\ ${ }^{3}$ Institute on Aging, Seoul National University College of Medicine, Seoul, Korea
}

Background: The relationship between economics and health has been of great interest throughout the years. The accumulated data is not sufficient enough to carry out long-term studies from the viewpoint of morbidity, although Korea National Health and Nutrition Examination Survey (KNHANES) was carried out yearly since 1998 in Korea. Thus, we investigated the effect of the 2008 global economic crisis on health indicators of Korea.

Methods: Health indicators were selected by paired t-test based on 2007 and 2009 KNHANES data. Age, gender, body mass index (BMI), smoking, drinking, exercise, education, income, working status, and stress were used as confounding factors, which were analyzed with logistic and probit analyses. Validation was done by comparing gross domestic product (GDP) growth rates and probit analyses results of 2007-2012 KNHANES data.

Results: Among several health indicators, the prevalence of hypertension and stress perception was higher after the economic crisis. Factors related with higher hypertension prevalence include older age, male gender, higher BMI, no current tobacco use, recent drinking, lower education levels, and stress perception. Factors related with more stress perception were younger age, female gender, current smoking, lower education levels, and lower income. GDP growth rates, a macroeconomic indicator, are inversely associated with hypertension prevalence with a one-year lag, and also inversely associated with stress perception without time lag.

Conclusion: The economic crisis increased the prevalence of hypertension and stress perception. In the case of GDP growth rate change, hypertension was an inversely lagging indicator and stress perception was an inverselyrelated coincident indicator.

Keywords: Economic Cycle; Economic Recession; Gross Domestic Product; Health; Hypertension; Stress 


\section{INTRODUCTION}

A number of studies have been conducted on the association between economics and health. Most of them have used mortality rather than morbidity as an indicator owing to the usability of the dataset. In recent years, as the scope of the investigation has extended, it has become possible to examine morbidity related to economics. The Korean National Health and Nutrition Examination Survey (KNHANES), which has been conducted since 1998, has made it possible to collect data related to morbidity.

Previous studies showed that mortality decreased as individual income or national economic status improved. ${ }^{1-4)}$ However, contrary to general expectations, mortality trends are negatively correlated to economic cycles, which means that mortality improves during economic recessions. ${ }^{5-9)}$ A macro-level study has also shown that expanding economic status was related to increasing mortality in elderly subjects, who mainly contributed to the mortality reported by the Organization for Economic Cooperation and Development (OECD), but Korea was excluded from this study because of insufficient data. ${ }^{10)}$ According to an Icelandic study on economic conditions and morbidity, the Icelandic economic collapse of 2008 was positively related to hypertension but not significantly related to cardiovascular disease. ${ }^{11)}$

In Korea, there have been some studies, albeit short-term ones, on the relationship between economic conditions and health indicators. It has also been shown that mortality tended to decrease during the foreign exchange crisis in $1997,{ }^{12)}$ but the results related to morbidity and medical care utilization were mixed depending on the type of disease or medical service. $^{13)}$

As shown in Table 1, the gross domestic product (GDP) growth rate of Korea was less than $1 \%$ in 2009, one year after the 2008 global economic crisis. ${ }^{14)}$ To the best of our knowledge, the relationship between economics and morbidity in Korea has not been extensively studied. We therefore investigated the effect of the 2008 global economic crisis on the health indicators of Korea using KNHANES IV (2007-2009).

Table 1. GDP and GDP growth rate of Korea

\begin{tabular}{lcccc}
\hline Year & $\begin{array}{c}\text { GDP, PPP } \\
\text { (constant 2011 } \\
\text { international \$) }\end{array}$ & $\begin{array}{c}\text { Growth rate } \\
\text { (annual \%) }\end{array}$ & $\begin{array}{c}\text { GDP percapita, PPP } \\
\text { (constant 2011 } \\
\text { international \$) }\end{array}$ & $\begin{array}{c}\text { Growth rate } \\
\text { (annual \%) }\end{array}$ \\
\hline 2007 & $1,356,355,629,235$ & 4.89 & 27,910 & 4.40 \\
2008 & $1,402,394,020,992$ & 3.39 & 28,650 & 2.65 \\
2009 & $1,412,316,217,889$ & 0.71 & 28,716 & 0.23 \\
2010 & $1,504,071,368,471$ & 6.50 & 30,440 & 6.00 \\
2011 & $1,559,446,834,232$ & 3.68 & 31,327 & 2.91 \\
2012 & $1,595,195,319,408$ & 2.29 & 31,901 & 1.83 \\
\hline
\end{tabular}

GDP, gross domestic product; PPP, purchasing power parity.

\section{METHODS}

\section{Data Source and Study Population}

We evaluated data from KNHANES, which has been conducted by the Korean Ministry of Health and Welfare among noninstitutionalized civilians in South Korea since 1998, in order to provide nationally representative and reliable statistical data. ${ }^{15,16)}$ We selected subjects over 30 years of age who had corrected hypertension data and who had participated in the surveys during KNHANES IV and V (2007-2012). All KNHANES participants signed an informed consent form.

\section{Variables}

This study is in accordance with the hypothesis that health indicators will not change in the short term unless big events related to health occur. Dependent variables were selected by a paired t-test based on the 2007 and 2009 KNHANES data, and a qualitative and limited dependent variable model was used for the selected dependent variables. Hypertension, diabetes mellitus, and dyslipidemia prevalence were chosen as objective health indicators, and stress perception, depressive symptom experience, and suicidal ideation were selected as subjective health indicators. A dummy variable was included to reflect the year effect, differentiating before and after the 2008 global economic crisis. Potential confounders included age, gender, body mass index (BMI), cigarette smoking, drinking, exercise, education, household income, and working status. Stress perception was also included as confounder when the dependent variable was hypertension. All estimates were weighted to represent the Korean population.

\section{Statistical Analyses}

The analyses comprised two parts: in the first, we assessed the effects of the 2008 global economic crisis using a model that introduced a dummy variable through KNHANES 2007-2009; in the second, we confirmed the stability of the models with dummy variables using KNHANES 2007-2012. After confirming that there were no definite differences between logistic and probit analyses in the first part of our analysis, we preferred probit analysis in the second part. Although probit analysis requires more computing power than logistic analysis owing to utilizing a cumulative distribution function of a standard normal distribution as a quantile function, it has an advantage of not only almost the same results but also diverse interpretation and application of them. ${ }^{17)}$ Analyses were conducted in SAS ver. 9.4 (SAS Institute Inc., Cary, NC, USA).

\section{RESULTS}

Table 2 depicts paired t-test results for the dependent variable candidates in matching samples based on 2007 and 2009 
Table 2. Paired t-test results for the dependent variable candidates

\begin{tabular}{|c|c|c|c|c|c|c|c|c|c|c|}
\hline \multirow{2}{*}{ Variable } & \multicolumn{3}{|c|}{2007} & \multicolumn{3}{|c|}{2009} & \multicolumn{3}{|c|}{ Pooled diff } & \multirow{2}{*}{$\begin{array}{c}\text { Satter thwaite } \\
\text { P-value }\end{array}$} \\
\hline & $\mathrm{N}$ & Mean & SD & N & Mean & SD & Mean & SD & P-value & \\
\hline Hypertension & 2,595 & 0.2813 & 0.4497 & 6,440 & 0.3138 & 0.4641 & -0.0325 & 0.4600 & $0.0024^{*}$ & $0.0021^{*}$ \\
\hline Diabetes & 2,452 & 0.1036 & 0.3048 & 5,975 & 0.1126 & 0.3162 & -0.0091 & 0.3129 & 0.2280 & 0.2209 \\
\hline Dyslipidemia & 2,388 & 0.1152 & 0.3193 & 5,984 & 0.1270 & 0.3330 & -0.0118 & 0.3292 & 0.1371 & 0.1301 \\
\hline Stress & 2,639 & 0.2588 & 0.4381 & 6,431 & 0.2894 & 0.4535 & -0.0306 & 0.4491 & $0.0032^{*}$ & $0.0028^{*}$ \\
\hline Depressive symptoms & 2,641 & 0.1518 & 0.3589 & 6,431 & 0.1662 & 0.3723 & -0.0144 & 0.3685 & 0.0911 & 0.0863 \\
\hline Suicidal thoughts & 2,634 & 0.1822 & 0.3861 & 6,429 & 0.1860 & 0.3892 & -0.0038 & 0.3883 & 0.6727 & 0.6713 \\
\hline
\end{tabular}

*Indicates P-value under 0.05 .

Table 3. Statistics on hypertension

\begin{tabular}{|c|c|c|c|c|c|c|c|c|}
\hline \multirow{2}{*}{ Variable } & \multicolumn{4}{|c|}{ Logistic distribution assumption } & \multicolumn{4}{|c|}{ Normal distribution assumption } \\
\hline & Estimate & SE & t-value & $P$-value & Estimate & SE & t-value & P-value \\
\hline Intercept & -9.0307 & 0.3825 & -23.61 & $<0.0001^{*}$ & -5.2808 & 0.2189 & -24.12 & $<0.0001^{*}$ \\
\hline Economic crisis & 0.1419 & 0.0620 & 2.29 & $0.0220^{*}$ & 0.0803 & 0.0362 & 2.22 & $0.0265^{*}$ \\
\hline Age & 0.0774 & 0.0029 & 26.45 & $<0.0001^{*}$ & 0.0455 & 0.0017 & 27.16 & $<0.0001^{*}$ \\
\hline Sex & -0.4646 & 0.0685 & -6.78 & $<0.0001^{*}$ & -0.2784 & 0.0401 & -6.94 & $<0.0001^{*}$ \\
\hline Body mass index & 0.1906 & 0.0088 & 21.59 & $<0.0001^{*}$ & 0.1111 & 0.0051 & 21.81 & $<0.0001^{*}$ \\
\hline Smoking & -0.1571 & 0.0753 & -2.09 & $0.0370^{*}$ & -0.0860 & 0.0437 & -1.97 & $0.0493^{*}$ \\
\hline Drinking & 0.1864 & 0.0616 & 3.03 & $0.0025^{*}$ & 0.1103 & 0.0362 & 3.05 & $0.0023^{*}$ \\
\hline Exercise & 0.0274 & 0.0345 & 0.79 & 0.4270 & 0.0185 & 0.0202 & 0.92 & 0.3593 \\
\hline Education & -0.0953 & 0.0319 & -2.99 & $0.0028^{*}$ & -0.0557 & 0.0188 & -2.96 & $0.0031^{*}$ \\
\hline Income & 0.0186 & 0.0255 & 0.73 & 0.4673 & 0.0082 & 0.0150 & 0.55 & 0.5836 \\
\hline Working & -0.0763 & 0.0614 & -1.24 & 0.2137 & -0.0461 & 0.0361 & -1.28 & 0.2020 \\
\hline Stress & 0.1164 & 0.0613 & 1.90 & 0.0577 & 0.0708 & 0.0358 & 1.98 & $0.0478^{*}$ \\
\hline
\end{tabular}

SE, standard error.

*Indicates P-value under 0.05 .

Table 4. Statistics on the perceived level of stress

\begin{tabular}{|c|c|c|c|c|c|c|c|c|}
\hline \multirow{2}{*}{ Variable } & \multicolumn{4}{|c|}{ Logistic distribution assumption } & \multicolumn{4}{|c|}{ Normal distribution assumption } \\
\hline & Estimate & SE & t-value & P-value & Estimate & SE & t-value & P-value \\
\hline Intercept & -0.8210 & 0.3182 & -2.58 & $0.0099^{*}$ & -0.4291 & 0.1898 & -2.59 & $0.0095^{*}$ \\
\hline Economic crisis & 0.1650 & 0.0552 & 2.99 & $0.0028^{*}$ & 0.0982 & 0.0328 & 2.99 & $0.0027^{*}$ \\
\hline Age & -0.0150 & 0.0025 & -6.00 & $<0.0001^{*}$ & -0.0090 & 0.0015 & -6.06 & $<0.0001^{\star}$ \\
\hline Sex & 0.3825 & 0.0629 & 6.09 & $<0.0001^{*}$ & 0.2279 & 0.0372 & 6.12 & $<0.0001^{\star}$ \\
\hline Body mass index & 0.0087 & 0.0074 & 1.18 & 0.2372 & 0.0050 & 0.0044 & 1.12 & 0.2620 \\
\hline Smoking & 0.2832 & 0.0679 & 4.17 & $<0.0001^{*}$ & 0.1676 & 0.0406 & 4.13 & $<0.0001^{*}$ \\
\hline Drinking & 0.0573 & 0.0537 & 1.07 & 0.2857 & 0.0335 & 0.0322 & 1.04 & 0.2972 \\
\hline Exercise & -0.0555 & 0.0309 & -1.80 & 0.0726 & -0.0342 & 0.0184 & -1.86 & 0.0635 \\
\hline Education & -0.0756 & 0.0302 & -2.50 & $0.0123^{*}$ & -0.0459 & 0.0180 & -2.55 & $0.0107^{\star}$ \\
\hline Income & -0.0734 & 0.0227 & -3.23 & $0.0012^{*}$ & -0.0439 & 0.0136 & -3.23 & $0.0012^{*}$ \\
\hline Working & 0.0786 & 0.0542 & 1.45 & 0.1471 & 0.0475 & 0.0325 & 1.46 & 0.1442 \\
\hline
\end{tabular}

SE, standard error.

*Indicates P-value under 0.05 .

KNHANES data. Hypertension prevalence among objective health indicators and stress perception among subjective health indicators demonstrated a significant increase in 2009 compared with 2007, that is, after the economic crisis.

The results of both logistic and probit analyses of hypertension prevalence are almost the same (Table 3). Although there are statistically significant differences regarding stress, the Pvalue was similar; the P-value of logistic and probit analyses were 0.057 and 0.047 , respectively. Our results demonstrate an increase in hypertension prevalence after the 2008 global economic crisis. Factors related to higher hypertension prevalence included older age, male gender, higher BMI, no current tobacco use, recent drinking, lower education levels, and higher stress perception. The results of both logistic and probit analyses of stress perception are also similar (Table 4). Factors related to greater stress perception were younger age, female sex, current smoking, lower education levels, and lower income.

In the second part of the analysis, we mainly used probit 
Table 5. Year effects of dependent variables by duration

\begin{tabular}{|c|c|c|c|c|c|c|c|c|c|}
\hline \multirow{2}{*}{ Duration } & \multirow{2}{*}{ Year } & \multicolumn{4}{|c|}{ Hypertension } & \multicolumn{4}{|c|}{ Stress } \\
\hline & & Estimate & SE & $\mathrm{t}$-value & P-value & Estimate & SE & t-value & P-value \\
\hline \multirow[t]{5}{*}{1 Year } & 2007-2008 & 0.0635 & 0.0364 & 1.74 & 0.0811 & 0.0293 & 0.0335 & 0.87 & 0.3821 \\
\hline & 2008-2009 & 0.0147 & 0.0268 & 0.55 & 0.5834 & 0.0661 & 0.0247 & 2.68 & $0.0074^{*}$ \\
\hline & 2009-2010 & 0.0455 & 0.0273 & 1.66 & 0.0960 & -0.0738 & 0.0252 & -2.92 & $0.0034^{*}$ \\
\hline & 2010-2011 & 0.0815 & 0.0520 & 1.57 & 0.1173 & -0.0085 & 0.0539 & -0.16 & 0.8746 \\
\hline & 2011-2012 & 0.0052 & 0.0524 & 0.10 & 0.9204 & -0.0347 & 0.0548 & -0.63 & 0.5261 \\
\hline \multirow[t]{4}{*}{2 Year } & 2007-2009 & 0.0803 & 0.0362 & 2.22 & $0.0265^{\star}$ & 0.0982 & 0.0328 & 2.99 & $0.0027^{*}$ \\
\hline & 2008-2010 & 0.0603 & 0.0281 & 2.15 & $0.0317^{\star}$ & -0.0107 & 0.0262 & -0.41 & 0.6827 \\
\hline & 2009-2011 & 0.0166 & 0.0511 & 0.32 & 0.7457 & -0.1435 & 0.0521 & -2.76 & $0.0058^{*}$ \\
\hline & 2010-2012 & 0.0732 & 0.0287 & 2.56 & $0.0106^{*}$ & -0.0658 & 0.0275 & -2.39 & $0.0166^{*}$ \\
\hline
\end{tabular}

$\mathrm{SE}$, standard error.

*Indicates P-value under 0.05 .

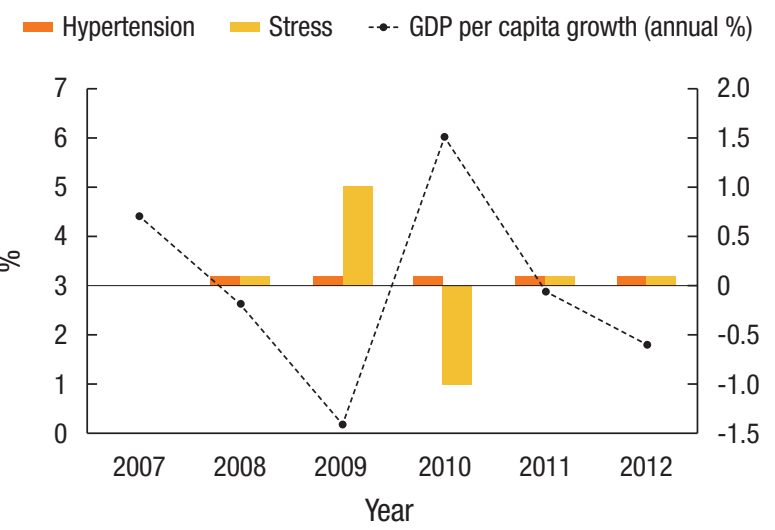

Figure 1. GDP per capita growth rate and 1-year effects of hypertension and stress. GDP per capita growth rates are calculated from GDP per capita, PPP, constant 2011 international $\$$ values. Left axis shows GDP per capita growth rate value as percentage (\%). Right axis shows arbitrary value of the year effect $(+1,0,-1)$ of the respective dependent variable. Red bars indicate hypertension and yellow bars indicate stress. Note that the bars are drawn at the last year of the duration of interest. The bar height of +1 means statistically significant year effect positively correlated to GDP per capita growth rate change, -1 means statistically significant year effect negatively correlated and 0 means statistically insignificant year effect. GDP, gross domestic product; PPP, purchasing power parity.

analysis to confirm the stability of the model, which included dummy variables to represent a year effect. The dummy variable for a year effect is included with the intention of effectively reflecting the economic environment, however this dummy variable might include other confounding effects not considered in this study. Therefore, we conducted analyses of both 1and 2-year periods from 2007-2012 data (Table 5). Regarding hypertension, the 2-year analyses of 2007-2009, 2009-2011, and 2010-2012 showed statistically significant differences, whereas none of the 1-year analyses did. Regarding stress perception, the 2-year analyses of 2007-2009, 2009-2011, and 2010-2012 and 1-year analyses of 2008-2009 and 2009-2010 showed statistically significant differences.

Figures 1 and 2 show GDP per capita growth rate and, respectively, 1-year and 2-year effects of hypertension and stress. According to the GDP per capita growth rate, stress perception changed more quickly than hypertension. GDP growth rates, a

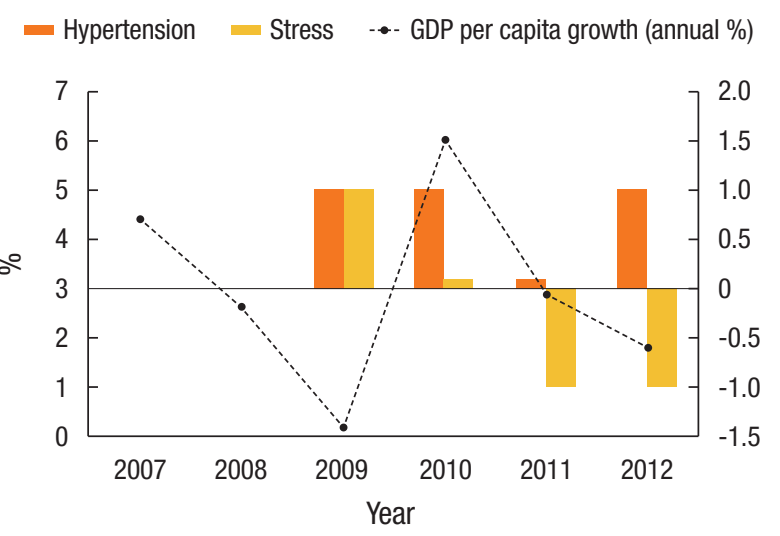

Figure 2. GDP per capita growth rate and 2-year effects of hypertension and stress. GDP per capita growth rates are calculated from GDP per capita, PPP, constant 2011 international \$ values. Left axis shows GDP per capita growth rate value as percentage (\%). Right axis shows arbitrary value of the year effect $(+1,0,-1)$ of the respective dependent variable. Red bars indicate hypertension and yellow bars indicate stress. Note that the bars are drawn at the last year of the duration of interest. The bar height of +1 means statistically significant year effect positively correlated to GDP per capita growth rate change, -1 means statistically significant year effect negatively correlated and 0 means statistically insignificant year effect. GDP, gross domestic product; PPP, purchasing power parity.

macroeconomic indicator, were inversely associated with hypertension prevalence with a 1-year lag and inversely associated with stress perception without lag. From the consistent results shown the relationship between the dependent variable and the economic environment, we concluded that the dummy variables effectively reflected the economic results.

\section{DISCUSSION}

This study aimed to examine the association between a macroeconomic change and health indicators. The 2008 global economic crisis might be inversely related to hypertension prevalence and stress perception, but because of the limitation of data, only short periods could be analyzed. In the recent global-level OECD study, Korea was excluded owing to insufficient GDP data. ${ }^{10}$ Although KNHANES-a systematic and representative nationwide survey-was conducted yearly since 1998, 
the accumulated data are not sufficient to carry out long-term studies regarding morbidity.

The cross sectional design of the data could be a limitation because individual paired data are unavailable, which might be improved using cohort studies like the Icelandic study. ${ }^{11)}$ However, the use of representative data from the general population allows the results to be easily generalized to the whole population.

Regarding the objective variables such as hypertension, diabetes mellitus, and dyslipidemia, it could be expected that only hypertension was related to short-term economic change, considering the pathologic physiology of the disease. Hypertension is explained by some theories of its pathogenesis involving intravascular volume, the autonomic nervous system, the reninangiotensin-aldosterone system, and vascular mechanisms. ${ }^{18)}$ Stress perception would affect the autonomic nervous system, which contributes to the pathogenesis of hypertension after a short-term economic crisis. On the other hand, other diseases such as diabetes mellitus, dyslipidemia, and malignancy take a longer time to manifest. Long-term data or a cohort study could be helpful to evaluate the effect of an economic crisis on these diseases.

To verify the model, we included a dummy variable and used the whole KNHANES IV and V dataset (2007-2012), which indicated the association between macroeconomic markers and health indicators. As shown in Figure 1, the drop in GDP growth rate did not appear to affect hypertension prevalence within 1 year after the economic crisis, whereas Figure 2 shows that hypertension prevalence increased in the following year after the drop in GDP growth rate.

As GDP growth rates decreased in 2007-2008 and 20082009, hypertension prevalence increased in 2009 and 2010, respectively. When the GDP growth rate rose in 2009-2010, hypertension prevalence was unchanged. After a drop in the GDP growth rate in 2010-2011, the prevalence increased again in 2012. These results indicate that GDP growth rates are inversely associated with hypertension prevalence with a 1-year lag, but a long-term dataset is needed to generalize these results.

Stress perception seems to increase with economic downturns and to decrease with upturns. Although GDP growth rates dropped in 2007-2008, economic growth remained at 3\%, and stress perception was unchanged. However, as GDP growth rates dropped to close to $0 \%$ in 2008-2009, stress perception significantly increased. As GDP growth rates climbed back up to $6 \%$ in $2009-2010$, stress perception significantly decreased. When GDP growth rates noticeably dropped in 2009, stress perception significantly increased, and with the remarkable upturn of the GDP growth rate in 2010, stress perception significantly decreased. From these patterns, we can conclude that GDP growth rates, a macroeconomic indicator, may be inversely associated with stress perception without lag.
We investigated a conjecture that economic changes affect health indicators using objective data. It demonstrated that GDP growth rates as a macroeconomic indicator were inversely associated with hypertension prevalence with a 1-year lag and inversely associated with stress perception with no year lag. Compared with the result that stress perception oscillates inversely with GDP growth rate cycles, hypertension prevalence increased only when the GDP growth rate decreased. In the case that the GDP growth rate increased, hypertension prevalence showed no change. With previous consideration, we concluded that the dummy variable of the year effects in the model reflects the macroeconomic environment effectively, which is proxied by the annual GDP growth rate. These results could be applicable in diverse clinical or public health areas, particularly if they are complemented with further investigations using long-term data.

\section{CONFLICT OF INTEREST}

No potential conflict of interest relevant to this article was reported.

\section{REFERENCES}

1. Benzeval M, Judge K. Income and health: the time dimension. Soc Sci Med 2001;52:1371-90.

2. Case A. Health, income and economic development. In: Pleskovic B, Stern N, editors. Annual World Bank Conference on Development Economics 2001/2002. Washington (DC): World Bank; 2002.

3. Lynch JW, Smith GD, Kaplan GA, House JS. Income inequality and mortality: importance to health of individual income, psychosocial environment, or material conditions. BMJ 2000;320:1200-4.

4. Smith JP. Healthy bodies and thick wallets: the dual relation between health and economic status. J Econ Perspect 1999;13:144-66.

5. Catalano R, Bellows B. Commentary: if economic expansion threatens public health, should epidemiologists recommend recession? Int J Epidemiol 2005;34:1212-3.

6. Ruhm CJ. Are recessions good for your health? Q J Econ 2000;115:61750.

7. Ruhm CJ. Commentary: mortality increases during economic upturns. Int J Epidemiol 2005;34:1206-11.

8. Tapia Granados JA. Increasing mortality during the expansions of the US economy, 1900-1996. Int J Epidemiol 2005;34:1194-202.

9. Tapia Granados JA, Ionides EL. Mortality and macroeconomic fluctuations in contemporary Sweden. Eur J Popul 2011;27:157-84.

10. Rolden HJ, van Bodegom D, van den Hout WB, Westendorp RG. Old age mortality and macroeconomic cycles. J Epidemiol Community Health 2014;68:44-50.

11. Asgeirsdottir TL, Olafsdottir T, Ragnarsdottir DO. Business cycles, hypertension and cardiovascular disease: evidence from the Icelandic economic collapse. Blood Press 2014;23:213-21.

12. Khang YH, Lynch JW, Kaplan GA. Impact of economic crisis on causespecific mortality in South Korea. Int J Epidemiol 2005;34:1291-301. 
13. Kim H, Chung WJ, Song YJ, Kang DR, Yi JJ, Nam CM. Changes in morbidity and medical care utilization after the recent economic crisis in the Republic of Korea. Bull World Health Organ 2003;81:567-72.

14. The World Bank. World DataBank: explore, create, share: development data [Internet]. Washington (DC): The World Bank; c2015 [cited 2014 Jul 13]. Available from: http://databank.worldbank.org/data/home. aspx.

15. Korea Centers for Disease Control and Prevention. The Fourth Korea National Health and Nutrition Examination Survey (KNHANES IV). Cheongju: Korea Centers for Disease Control and Prevention; 2008.
16. Korea Centers for Disease Control and Prevention. The Fifth Korea National Health and Nutrition Examination Survey (KNHANES V). Cheongju: Korea Centers for Disease Control and Prevention; 2010.

17. Cramer JS. The origins and development of the logit model. In: Cramer JS, editor. Logit models from economics and other fields. Cambridge: Cambridge University Press; 2003. p. 149-58.

18. Longo D, Fauci A, Kasper D, Hauser S, Jameson J, Loscalzo J. Harrison's principles of internal medicine. 18th ed. New York: McGraw Hill Medical; 2012. 